\title{
OSTEOTOMY AS AN INDICATOR OF ANTISEPTIC SURGICAL PRACTICE
}

\author{
by
}

\section{T. H. PENNINGTON *}

In the UK Government's 1993 review of science and technology the statement is made that "the interval between scientific discovery and practical application is diminishing".' Two changes might explain such an acceleration of the acceptance of scientific innovation. Alterations may have occurred in the way that scientific ideas are spread, with concomitant increases in their rates of diffusion. On the other hand, a decline may have occurred in the resistance to innovation, as epitomized by Max Planck's comment that "a scientific truth does not triumph by convincing its opponents and making them see the light, but rather because its opponents eventually die, and a new generation grows up that is familiar with it". ${ }^{2}$ Historians of science and medicine have paid a good deal of attention to such changes in their studies on the diffusion of ideas and technologies and their reception. An instance is the introduction of antiseptic methods into surgery. The differences between the explanations for post-operative inflammation and sepsis that were accepted and promulgated by surgeons in the 1860 s and in the 1890 s are so greatparticularly with respect to germ theory-and their impact on practice and research was so profound, that a good case can be made for categorizing the changes as a Kuhnian paradigm shift. $^{3}$

Lister's own papers, and the accounts by his pupils and the adherents to his system, provide a full description of the development of his methods, its rituals, and its impact. ${ }^{4}$ Despite the changes and modifications that Lister included during its first decade, its underlying principle remained constant - "the exclusion of all microbes from wounds"and its central technical feature, the use of carbolic acid as an antibacterial agent, remained in essence unchanged. In its full development, the method used carbolic to treat the skin

\footnotetext{
* Professor T. H. Pennington, Department of Medical Microbiology, University of Aberdeen, Medical School, Foresterhill, Aberdeen AB9 2ZD.

I thank Dr C. I. Pennington for providing the data on the operations in Glasgow Hospitals and for reading the manuscript. p. 1 .

' Realising our potential. A strategy for science, engineering and technology, Cm 2250, London, HMSO, 1993,

${ }^{2}$ M. Planck, Scientific autobiography, transl. F. Gaynor, London, Williams and Norgate, 1950, pp. 33, 34.

${ }^{3}$ For definitions of such paradigms, T. Kuhn's own work The structure of scientific revolutions, Chicago University Press, 1970, should be consulted. It is self-evident that antisepsis played a significant role in this shift, at least in the preliminary phases of its developments.

${ }^{4}$ J. Lister, The collected papers, vol. 2, pt. 3, "The antiseptic system", pp. 1-371. Oxford, Clarendon Press, 1909; W. W. Cheyne, Antiseptic surgery. Its principles, practice, history and results, London, Smith Elder, 1882; W. H. Ogston, H. H. Cowan and E. H. Smith, Alexander Ogston, Aberdeen University Press, 1943.
} 


\section{Osteotomy as an indicator of antiseptic surgical practice}

before operations, as a "guard" during them, and as an essential component of wound dressings. ${ }^{5}$ Surgical instruments and sponges were steeped in it, surgeons' hands were dipped in it, catgut was prepared and kept in it, and the steam spray producer was used to envelop those involved in operations and wound dressing in a cloud of it. Two long papers published in the Lancet in 1867 and in 1875 mark the beginning and end of Lister's original contributions to the method. ${ }^{6}$ During this period rather little direct evidence had emerged to support his hypothesis "that the essential cause of suppuration in wounds is decomposition, brought about by the influence of the atmosphere", the septic property of the atmosphere depending "not on the oxygen or any gaseous constituent, but on minute organisms suspended in it", and his defence of the idea remained an indirect one, relying on case reports and the analysis of results of surgical treatment before and after its introduction. ${ }^{7}$

Although much has since been written about the Listerian method, ${ }^{8}$ obscurity and uncertainty continue to surround many of the details of its implementation in different centres, the nature and degree of resistance to it, and its role as a precursor to the development and introduction of aseptic methods. Particular problems are associated with the use of quantitative data to evaluate its effect on surgical practice. A substantial part of the literature published on antiseptic surgery at the time of its introduction and development was concerned with the statistical evaluation of its efficacy, with particular emphasis on case fatality rates. ${ }^{9}$ Medical historians still pay a good deal of attention to these numerical outcome indicators. ${ }^{10}$ However, the absence of controls, the heterogeneity of cases, the small number of operations being done in any one hospital and the absence of any information about the aetiology of infections in surgical patients for most of the period under study make the evaluation of these statistics a very difficult task. ${ }^{11}$ Other confounding effects also reduce the utility of case fatality rates for this task. Thus David Hamilton has

${ }^{5}$ Cheyne, op. cit., note 4 above, pp. 67-95.

${ }^{6} \mathrm{~J}$. Lister, 'On a new method of treating compound fracture, abscess, etc., with observations on the condition of suppuration', Lancet, 1867, i: 326-9, 357-9, 387-9, 507-9; ii: 95-6; and 'On recent improvements in the details of antiseptic surgery', Lancet, 1875, i: 365-7, 401-2, 434-6, 468-70, 603-5, 717-19, 787-9.

${ }^{7}$ R. Koch, Untersuchungen über die Aetiologie der Wundinfectionskrankheiten, Vogel, Leipzig, 1878 (English translation: Investigation into the etiology of traumatic infective diseases, transl. W. W. Cheyne, London, New Sydenham Society, 1880). The quotations are from J. Lister, 'On the antiseptic principle in the practice of surgery', Br. med. J., 1867, ii: 246.

${ }^{8}$ L. Granshaw, "Upon this principle I have based a practice": the development and reception of antisepsis in Britain, 1867-90', in J. V. Pickstone (ed.), Medical innovations in historical perspective, Basingstoke, Macmillan, 1992, pp. 17-46.

${ }^{9}$ Cheyne, op. cit., note 4 above.

${ }^{10}$ A. J. Youngson, The scientific revolution in Victorian medicine, London, Croom Helm, 1979, 157-211.

"' For a contemporary review of bacteriological studies on wound infections see R. Koch, op. cit., note 7 above. This monograph shows clearly that the issues faced by the investigators of the aetiology of wound diseases were complex. Dissecting out the matrix of relationships between classical nosological categories such as suppuration, pyaemia and septicaemia, and the increasing number of bacterial taxa being described at this time (e.g., Micrococcus, Staphylococcus, Streptococcus) was one such problem; it received particular attention in the late 1870 s and the 1880s. Detailed studies such as those of Ogston on abscesses (A. O. Ogston, 'Ueber Abscesse', Archiv für Klinische Chirurgie, 1880, 25: 588-600, 'Report upon micro-organisms in surgical diseases', $B r$. med. J., 1881, i: 369-75) and Fehleisen on erysipelas (F. Fehleisen, Die Aetiologie des Erysipels, Berlin, Fischer, 1883) were persuasive at this time because they were concerned with particularly well-defined clinical entities and because both clinical and experimental evidence indicated a simple one-to-one relationship between disease category and pathogen; the bacteriological findings of these workers were focused taxonomically at the generic level, however. Controversy attended other work, e.g., the role of micrococci in wound infections (e.g., A. O. Ogston, 'Micrococcus poisoning', J. Anat. Physiol., 1882, 16: 526-67, and 17: 24-58; W. W. Cheyne, 'Report on micrococci in relation to wounds, abscesses and septic processes', Br. med. J., 1884, ii: 553-6, 599-605, 645-7. 


\section{T. H. Pennington}

proposed that part of the decline in the incidence of post-operative infections which occurred in the 1870s in Lister's hospital, the Glasgow Royal Infirmary, was due to improvements in host defences which, in turn, followed a decline in undernourishment in that city. ${ }^{12}$ At about this time the nineteenth-century pandemic of scarlet fever came to an end ${ }^{13}$ in Scotland mean annual mortality rates from this disease fell more than tenfold between $1867-70$ and $1901-10 .{ }^{14}$ Scarlet fever is but one clinical manifestation of infection with Streptococcus pyogenes and it is not unreasonable to suppose that the virulent strains of the organism which circulated during the pandemic played an important role in the causation of suppuration, pyaemia, and hospital gangrene, and that their decline may have contributed to the diminution of post-operative case fatality rates.

The purpose of this paper is to demonstrate that by focusing on a single operationosteotomy-useful information can be obtained about the employment of antiseptic techniques in different centres. This approach also allows estimates to be made of the rate of diffusion and uptake of new technology in the last quarter of the nineteenth century.

Osteotomy is "the section, or surgical fracture, of a bone with or without the removal of osseous tissue. Its objective is the elimination or mitigation of deformity". ${ }^{15}$ The history of the operation before the introduction of antisepsis has been reviewed by William Adams, William Macewen, A. K. Bowman, and Roger Cooter. ${ }^{16}$ The event highlighted as being particularly important in its development was B. von Langenbeck's introduction in 1852 of subcutaneous osteotomy, in which the bone to be fractured was divided almost completely with a small straight-pointed saw manipulated through a small skin incision. By avoiding the creation of a large open wound and by trying to exclude air from the operating site it was hoped to prevent post-operative inflammation and suppuration. However, indirect and direct evidence supports the view that the subcutaneous approach did not, in itself, reduce these post-operative complications to an acceptable level. Thus the number of subcutaneous osteotomies reported in hospital statistics and the surgical literature remained small for the quarter-century after its introduction, an indication that its lack of success made it unpopular. ${ }^{17}$ Direct evidence about outcomes is contained in the remarks of contemporary

${ }^{12}$ D. Hamilton, 'The nineteenth-century surgical revolution-antisepsis or better nutrition?' Bull. Hist. Med., 1982, 56: 30-40.

${ }^{13}$ A. R. Katz, and D. M. Morens, 'Severe streptococcal infections in historical perspective', Clinical infectious Diseases, 1992, 14: 298-307.

${ }^{14}$ C. I. Pennington, 'Mortality, public health and medical improvements in Glasgow 1855-1911', PhD thesis, University of Stirling, 1977.

is A. K. Bowman, The life and teaching of Sir William Macewen, London, Edinburgh, and Glasgow, W. Hodge and Co, 1942, p. 177.

${ }^{16}$ W. Adams, 'On subcutaneous osteotomy', Br. med. J., 1879, ii: 604-6; W. Macewen, On osteotomy, London, J. and A. Churchill, 1880; Bowman, op. cit., note 15 above; R. Cooter, Surgery and society in peace and war: orthopaedics and the organization of modern medicine, 1880-1948, Basingstoke, Macmillan, 1993.

${ }^{17}$ Thus in textbooks of this period osteotomies are described as rare, unusual and bold operations, e.g., Sir William Fergusson, A system of practical surgery, 5th ed., London, John Churchill, 1870, p. 387: "In examples of bony anchylosis at the knee with the limb greatly bent, it has been proposed by Dr. J. R. Barton, of Philadelphia, to expose the anterior surface of the lower end of the femur by raising a triangular flap, and thereafter to cut out a portion of the bone in a wedge-shape so that the limb may be straightened as the cut surfaces of the bone are approximated. This proceeding has been done with great success by Dr. Barton, and also by Professor Gibson of the same city. In Dr. Barton's case the limb was gradually made straight in the progress of the treatment. At first the gap in the bone was filled with dressing, and during the stages of suppuration and granulation of the member was brought into the desired attitude. I do not suppose that such a proceeding has ever been attempted in this country, yet it seems worthy of imitation, for the advantages seem to have been great in both these instances. Dr. Barton's patient could walk with ease at the end of eight months, and could mount his horse with facility, or 


\section{Osteotomy as an indicator of antiseptic surgical practice}

surgeons. Thus "of those operated on with the saw, about $9 \%$ have died; some escaped by the skin of their teeth after long suppuration; a very great majority have done well. Yet the results are not sufficiently favourable to recommend to my mind that form of operation". ${ }^{18}$ The same paper graphically expresses the fate that could befall individuals after this operation, which was not a life-saving measure but was done at the discretion of the surgeon and the patient to relieve deformity: "the patient, after the surgeon has done his work, is left with a compound fracture, the broken bone lying very deeply-and if, in this depth, pus forms, the patient might perhaps escape with his life, but only after a long illness and much suffering, or he may die, exhausted by discharge and pain". ${ }^{19}$

The first osteotomies which tested the possibility that the application of antiseptic principles might prevent these complications were done by Richard Volkmann in Halle in August 1874. Under "die Schutzkraft der Lister'schen Verbände" (the protective influence of Listerian dressings), two patients with anklyosed knees were operated on; detailed descriptions of the procedures were published in December of that year. ${ }^{20}$ The next reported antiseptic osteotomy, and the first to rectify the deformity of knock-knee due to rickets, was undertaken by Thomas Annandale in Edinburgh in March 1875. He removed part of the articular end of the right femur "under the spray"; the excised bone was displayed at a meeting of the Edinburgh Medico-Chirurgical Society on 7th April following and the operation was described in detail in the July 1875 issue of the Edinburgh Medical Journal with the concluding comment that "the employment of the antiseptic treatment in this and similar operations I consider most valuable, and I must confess that it is my confidence in this treatment which led me to freely incise so important a joint, and to carry out the proceeding described". ${ }^{21}$ On the 11 April 1875 Macewen in Glasgow performed an open antiseptic osteotomy on an ankylosed right knee. The first published reference to this case was made in his 1878 'Clinical lecture on antiseptic osteotomy', in which he claimed it as the first such operation to be performed in Britain. ${ }^{22}$ The apparent discrepancy between this claim and the dates given in Annandale's publications on his first antiseptic osteotomy-to which Macewen made no reference-was further emphasized when Macewen stated in a second paper published later in 1878 that "in the Lancet for March 30th 1878 I stated that

travel on foot forty or fifty miles in a day". See also T. Billroth, Lectures on surgical pathology and therapeutics translation of 8th ed., London, New Sydenham Society, 1878, vol. 2, p. 219: "The results of [subcutaneous osteotomy], which I have often been compelled to perform, have hitherto been extremely favourable. In most cases the wound through the skin healed by the first intention and the treatment was then that of a simple fracture. The operation will, however, always be a rare one, because extreme curvatures from rachitis occur but seldom." For ankylosed knees he recommended forced extension under chloroform- "brisement forcé"-rather than an operation, with the added comment that "you must not expect these knees ... to resume their natural beautiful shape ... as we are not obliged, like the Scotch, to go about with bare knees, [their] shape is not of much importance ..." (vol. 2, p. 289).

${ }^{18} \mathrm{R}$. Barwell, 'Clinical lectures on antisepticism in sections and resections', Br. med. J., 1877, i: 506-7, 541-3, on p. 506 .

${ }^{19}$ Ibid. Billroth's attitude to resection (including subcutaneous osteotomy) is summarized by his comments on the application of this type of procedure to the elbow: “ . . if all goes well [Billroth's italics] we are able to make a false joint which is tolerably useful. The result, however, is not certain and we cannot always control it. Who would risk his life to get rid of a stiff elbow-joint?" (op. cit., note 17 above, vol. 2, p. 292).

${ }^{20}$ R. Volkmann, 'Zwei Fälle von Diaphysenosteotomein wegen Kniegelenksankylosen', Berliner Klinische Wochenschrift, 1874, 11: 629-31.

${ }^{21} \mathrm{~T}$. Annandale, 'On a new operation for the cure of a certain case of aggravated "knock-knee", Edinburgh med. J., 1875, 21: 18-20.

${ }^{22}$ W. Macewen, 'Clinical lecture on antiseptic osteotomy', Lancet, 1878, i: 449-50. 


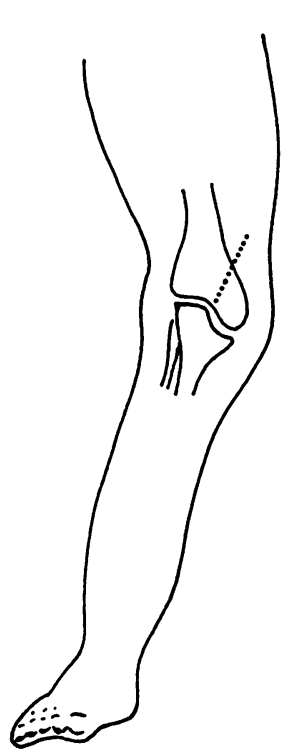

a.

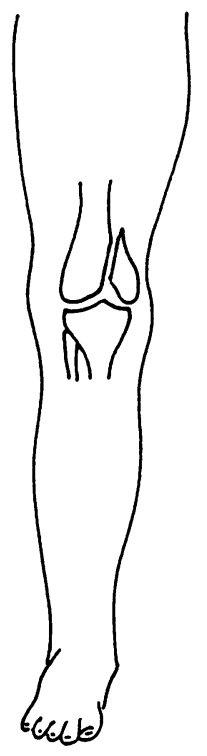

b.

Figure: Ogston's osteotomy: (a) line of division of internal condyle, (b) position after the operation.

the first osteotomy performed by me was the first antiseptic osteotomy performed in Britain; this has been accepted". ${ }^{23}$ In his book on osteotomy he clarified his position by designating Annandale's operation an osteo-arthrotomy-"a partial excision of the knee joint rather than an osteotomy, in its restricted sense". ${ }^{24}$

No controversy is associated with Alexander Ogston's operation for genu valgum (knock-knee), first done on the 17 May 1876 in Aberdeen. In this the internal condyle was almost completely severed from the femur using an Adams saw, the line of the division being known as Ogston's line (Figure). The final separation of the condyle is made by forcibly straightening the leg by bending it inwards using the operator's knee as a fulcrum. In the description of this part of his first operation Ogston wrote that the "remaining connexions of the condyle with the femur gave way with a crack on the application of very moderate force, and instantly the leg became as straight as a healthy limb ... The whole of the operation was conducted under carbolic spray, with a minute observance of Lister's antiseptic precautions, and the limb was put up in antiseptic dressings" (Ogston's italics). $^{25}$ Ogston's first paper on his operation appeared in March 1877 and was accompanied by two plates showing the patient's left leg operated on and bandaged, diagrams of Ogston's line and the position of the bones after operation, and a "copy of a

${ }^{23} \mathrm{~W}$. Macewen, 'Lecture on antiseptic osteotomy for genu valgum, genu varum, and other osseous deformities', Lancet, 1878, ii: 911-14, on p. 914.

${ }^{24}$ Macewen, op. cit., note 16 above, p. 103.

${ }^{25}$ A. O. Ogston, 'The operative treatment of genu valgum', Edinburgh med. J., 1877, 22: 782-4, on p. 784. 
Osteotomy as an indicator of antiseptic surgical practice

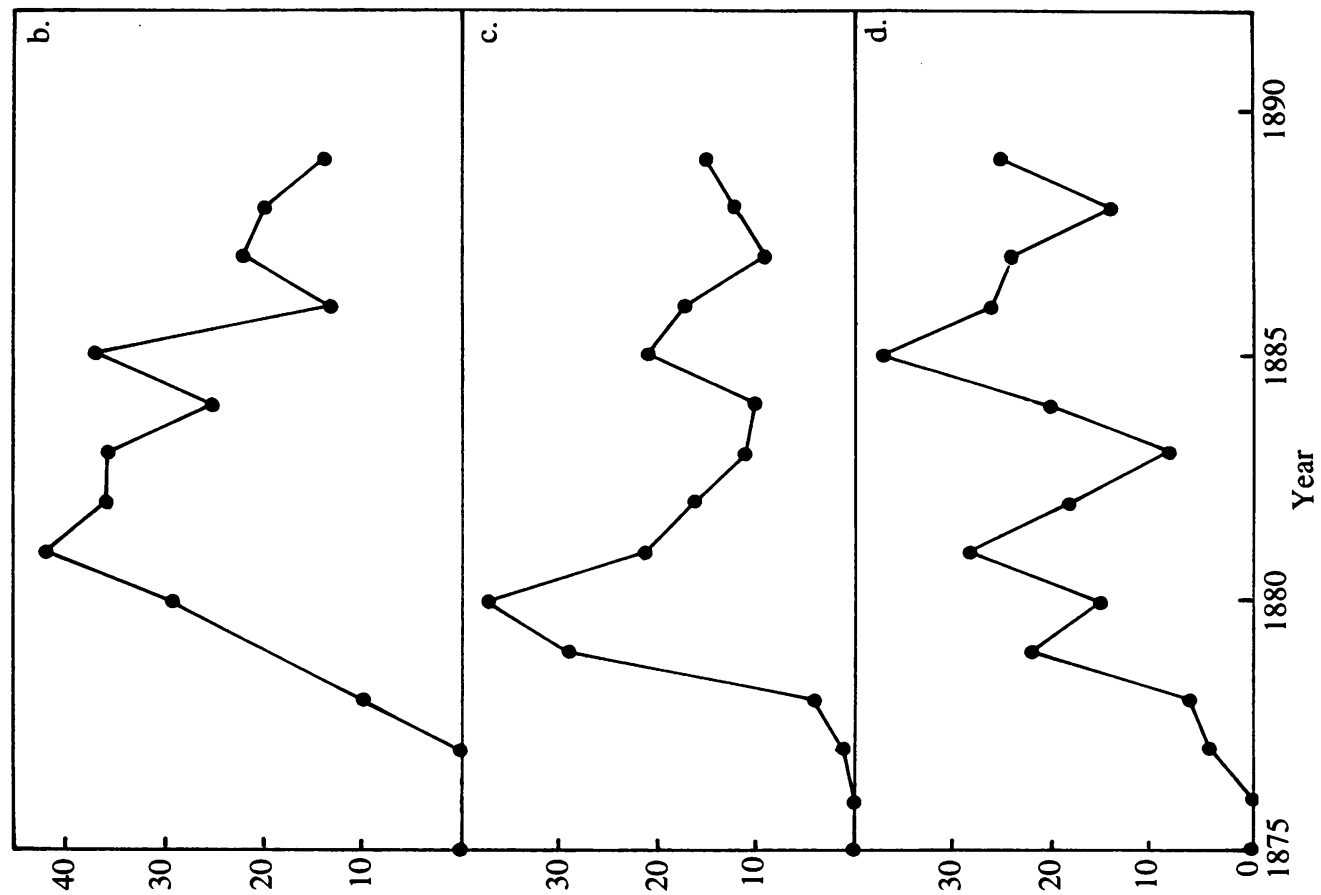

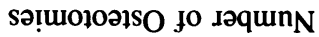

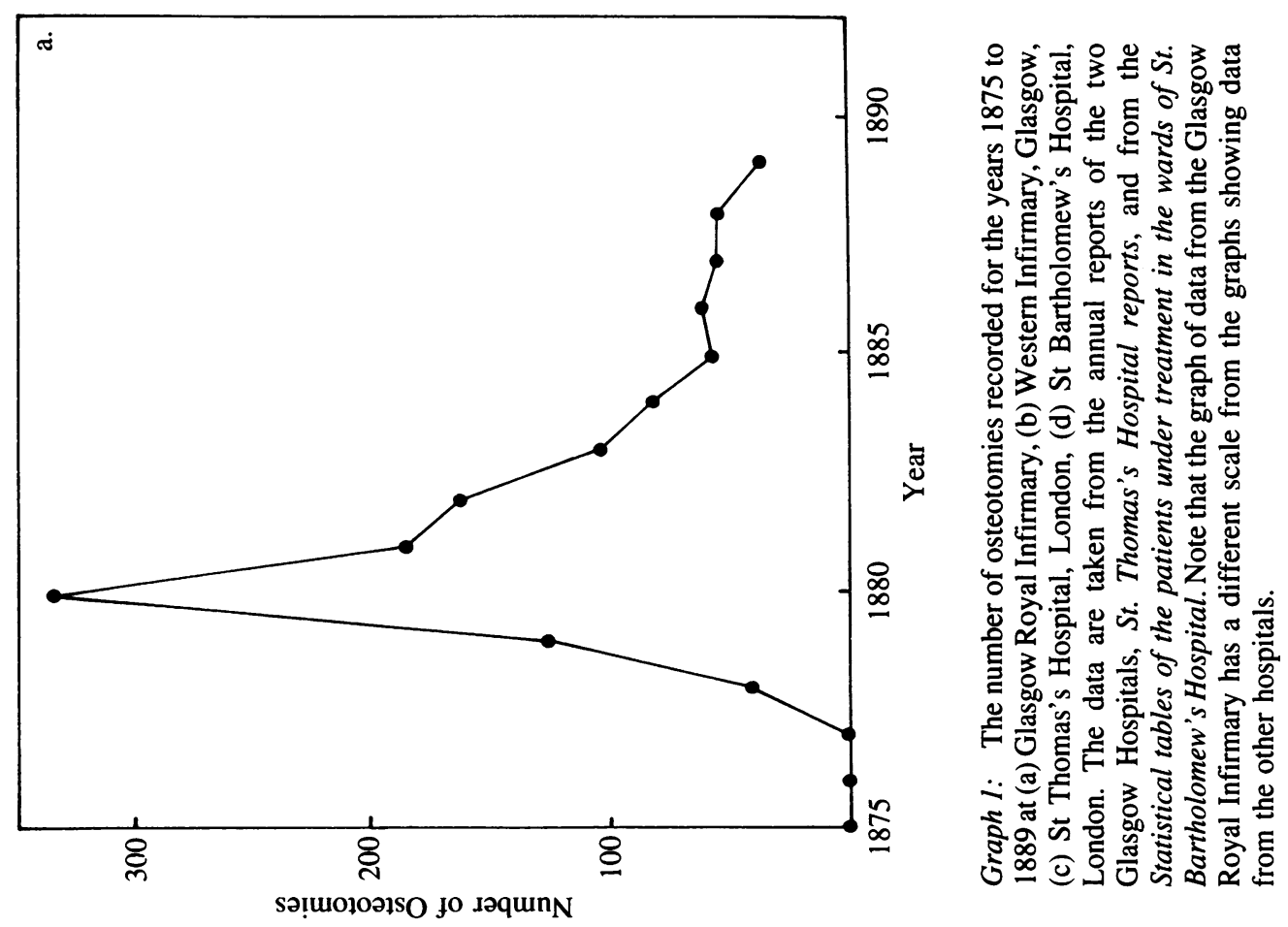




\section{T. H. Pennington}

photograph of the patient when cured. ${ }^{26}$ He presented details of this case and those of a second osteotomy at the Congress of the Deutsche Gesellschaft für Chirurgie in Berlin on the 4 April 1877; the text of his presentation was also published in full in German in the same year. ${ }^{27}$ The first antiseptic osteotomies in England were done by Richard Barwell, who operated on three ankylosed knees at the Charing Cross Hospital in November and December $1876 .{ }^{28}$ From about this time osteotomies began to be done with increasing frequency in British hospitals. Examination of the statistical reports of St Thomas's and St Bartholomew's Hospitals, the Royal and Western Infirmaries of Glasgow, and Aberdeen Royal Infirmary showed that 1877 was the first year that an entry for the operation appeared in these publications; nine operations were reported in that year. The number of operations done at these centres in 1878 increased more than sevenfold, to sixty-seven, with another major increase being recorded for the following year. Details of the number of osteotomies carried out between 1875 and 1889 at four of these hospitals are shown in Graph 1 (published records of the operations done at Aberdeen Royal Infirmary are incomplete for this period). It is clear that by 1880 osteotomy had become a well established procedure in Scotland and London.

Particularly noteworthy was the very large number of operations done at Glasgow Royal Infirmary with a peak in 1880 of 335 procedures, and the substantial decline that occurred thereafter. The majority were performed by Macewen, who, by 1884 , had recorded a personal series of 1,800 osteotomies. ${ }^{29}$ The development of his other interests may have prevented his continuing such a high level of activity. ${ }^{30}$ On the other hand, the decline may possibly have occurred because these efforts had relieved so many individuals with rickety deformities in the west of Scotland that a shortage of cases appropriate for operative treatment had developed. ${ }^{31}$

Direct evidence that the osteotomists active at this time used antiseptic methods is contained in the papers of Annandale, and John Chiene in Edinburgh, Ogston in Aberdeen, Macewen in Glasgow, Thomas Jones in Manchester, and Robert Parker and Barwell in London. ${ }^{32}$ At another London hospital, St Thomas's, William MacCormac was an active

\footnotetext{
${ }^{26}$ Ibid., pp. 784, 785.

${ }^{27}$ A. O. Ogston, 'Zur operativen Behandlung des Genu Valgum', Archiv fur Klinische Chirurgie, 1877, 21: $537-46$.

${ }^{28}$ Barwell, op. cit., note 18 above.

${ }^{29}$ W. Macewen, 'Osteotomy for genu valgum', Lancet, 1884, ii; 536-7.

${ }^{30}$ Macewen's range of other interests at this time is shown by his publications; between 1879 and 1881 he wrote on endotracheal intubation and the treatment of croup and diphtheria ( 3 papers), the radical cure of hernia, intracranial and skull surgery (4 papers), the differential diagnosis of coma, bone transplantation, chromic catgut, and blood transfusion. He performed his first intracerebral operation on a living patient in 1881 (Case 30 in W. Macewen, Pyogenic infective diseases of the brain and spinal cord, Glasgow, Maclehose, 1893). Macewen and Ogston developed their operations and vigorously publicized their methods and results at a time when both could be considered to be candidates "in waiting" for the Regius Chairs of Surgery in their local universities of Glasgow and Aberdeen. Whether or not this circumstance served as an impetus for Macewen's productivity and Ogston's research work, their appointment to these posts eventually followed (Macewen in 1892 and Ogston in 1882), lending support to Anderson's thesis that a chair in medical and divinity faculties of Scottish universities was the reward of a successful career (R. D. Anderson, 'Scottish university professors, 1800-1939: profile of an elite', in Scott. econ. soc. Hist., 1987, 7: 27-54).

${ }^{31}$ The assumption is made here that the majority of Macewen's cases were drawn from Glasgow and its environs. Some came from other parts of Scotland and from Ireland (op. cit., note 16 above).

${ }^{32}$ Annandale, op. cit., note 21 above; J. Chiene, 'The treatment of knock knee', Edinburgh med. J., 1876, 24: 878-82; Ogston, op. cit., note 25 above; Macewen, op. cit., note 22 above; T. Jones, 'Short notes of a dozen cases
} 


\section{Osteotomy as an indicator of antiseptic surgical practice}

osteotomist and a proponent of antisepsis. ${ }^{33}$ George Callender's description in 1878 of a series of five Ogston's osteotomies at St Bartholomew's does not mention antisepsis. ${ }^{34}$ However, the likelihood that he was using Listerian methods, at least in part, is supported by the description in the same paper of his dressing regime for compound fractures, in which wound cleansing by 1/20 carbolic was followed by the application of lint soaked with carbolized oil. At the 1884 International Medical Congress in Copenhagen, Macewen reported the results of his survey on osteotomies done by British hospital surgeons. ${ }^{35}$ Thirty-seven replied in detail. The spray and other Listerian precautions were used by 34 ; 3 conducted the operation by the open method. In terms of anatomical approach most respondents used either Macewen's supracondylar method (22 surgeons exclusively, 11 sometimes) or Ogston's operation ( 3 exclusively, 8 sometimes). ${ }^{36}$ Of the 1,118 limbs operated on, recovery was claimed for 1,113; suppuration occurred in 41 cases. Macewen reported separately and simultaneously on his own cases; he had osteomized 804 limbs, with 8 cases developing suppuration.

The increase in the number of osteotomies done in hospitals in Britain after 1877 was paralleled by an increase in the number of publications describing or discussing the operation. Graph 2 shows the temporal distribution of papers and books on the operative treatment of genu valgum and osteotomy published between 1875 and 1885 and listed in the Index-catalogue to the U.S. Army Surgeon-General's Library. A substantial proportion- 40 per cent - of the 134 publications appeared in 1879 and 1880; the titles of 24 per cent indicate that the main aim was to discuss, describe or criticize the procedures of Ogston or Macewen. The majority (12 out of 19) of books and papers on Ogston's operation were published in Germany or Austria-Hungary.

In this paper evidence has been presented which shows that osteotomy became a well established surgical procedure between the years 1878 and 1880 in many British hospitals. Two conditions must have been satisfied for this to occur. First, the technical developments necessary for conducting the procedure successfully must have have been made. Second, evidence of its success and its superiority over previous therapeutic approaches must have been obtained and promulgated in a way which caused a significant number of surgeons to adopt it. It may even have become fashionable. ${ }^{37}$

of subcutaneous osteotomy', Br. med. J., 1879, ii: 613-14; R. W. Parker, 'Subcutaneous osteotomy in young children', Br. med. J., 1878, ii: 611-13; Barwell, op. cit., note 18 above.

${ }^{33}$ W. MacCormac, 'Report of British Medical Association annual meeting, Cork, August 1879', Br. med. J., 1879, ii: 321; and 'Antiseptic surgery: an address delivered at St Thomas's Hospital, with subsequent debate', $B r$. med. J., 1880, i: 927-99.

${ }^{34}$ G. W. Callender, 'Seven years of hospital practice', St Bartholomew's Hospital reports, 1878, 15 : $183-95$.

${ }^{35}$ Macewen, op. cit., note 29 above.

${ }^{36}$ Macewen, op. cit., note 16 above.

${ }^{37}$ The utility of the term "fashion" in science is discussed by Barber ("The functions and dysfunctions of "fashion" in science: a case for the study of social change', in B. Barber, Social studies of science, New Brunswick and London, Transaction Publishers, 1990, 115-31). There seems to be merit in his view that to ascribe changes to "fashion" gives a name to a problem rather than accounting for it, that the term is sociologically vague and morally invidious, and that its use should be replaced by analyses of the types, rates, sources, the consequences of change, and the responses of scientists to that change. He follows his own example by discussing determinants of change such as new ideas and new methods, and he points out that "even if those who follow others into a 'fashionable' field are less than completely original and autonomous, they may be showing more originality and autonomy in recognizing a good new idea and pursuing it than in staying with some older unprofitable line", pp. 122, 123. 


\section{T. H. Pennington}

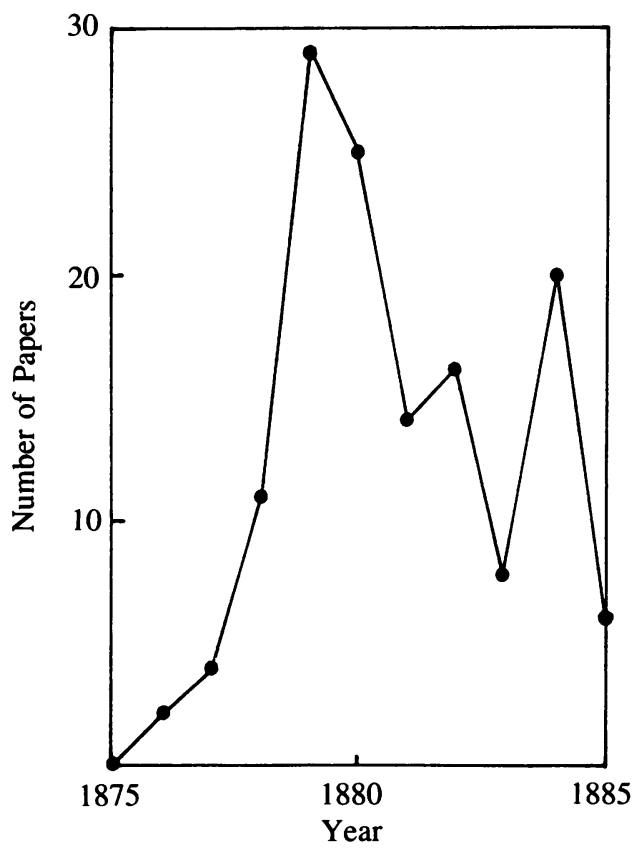

Graph 2: The number of papers recorded in the Index-catalogue of the library of the Surgeon-General's office, U.S. Army, under the heading "Knee joint (surgery of)" and with reference to "knock knee", "genu valgum" or "osteotomy" in their titles. Data for the years 1875 to 1885 are plotted. From vol. 7 (Insignarés-Leghorn), 1886. (Washington, D.C., U.S. Government Printing Office.)

Two types of technical developments in the history of osteotomy can be distinguished: general developments in surgery, notably anaesthesia and antisepsis, and the evolution of the anatomical approach used in the operation. In the descriptions of their own operations the two chief innovators in the latter field, Ogston and Macewen, made firm links between both types of development. Thus Macewen's major papers in the Lancet in 1878 referred in their titles to "antiseptic osteotomy", and Ogston went out of his way to emphasize his Listerian methods in his. Similar links were made in many of the publications of other osteotomists. Also noteworthy is the role played by osteotomy in the development and refinement of antisepsis; osteotomies accounted for 10 of the 144 operations performed by V. von Bruns without the spray and described in his famous paper "Fort mit dem Spray!". ${ }^{38}$ These observations support the hypothesis that the development of antisepsis was an important prerequisite for the establishment of osteotomy as a common procedure; the contrary view would be strengthened if is could be shown that some of the surgeons who contributed to the massive increase in the number of osteotomies after 1878 deliberately eschewed antiseptic methods. In Macewen's 1884 survey three surgeons conducted osteotomies by the "open method" rather than under the spray. ${ }^{39}$ It is not clear

\footnotetext{
${ }^{38}$ V. von Bruns, 'Fort mit dem Spray!', Berliner Klinischer Wochenschrift, 1800: 17: 609-11.

${ }^{39}$ Macewen, op. cit., note 29 above.
} 
from Macewen's description whether the "open method" incorporated any Listerian components, and he does not say how many operations these surgeons had done during the survey period. The statistical reports of operations performed in the teaching hospitals examined in this study contain no information about the use of antiseptic methods, and, in general, do not name the operators, thus precluding the possibility of identifying osteotomies carried out by surgeons known to use Listerian techniques. Because comparative statistics on osteotomies done with and without antisepsis are not available, it is not possible to test the hypothesis that morbidity and case fatality rates from the operation done without antisepsis under the conditions prevailing in the late 1870s and early 1880 s would have been high enough to prevent the operation becoming widely adopted. However, the limited evidence that is available from the pre-antiseptic period provides some support for this view; ${ }^{40}$ the 9 per cent case fatality rate quoted for procedures at this time compares very unfavourably with Macewen's figures of less than 1 per cent of cases developing suppuration in a series of antiseptic osteotomies on 804 limbs. ${ }^{41}$ Whether or not outcomes as good as this could have been obtained without antisepsis, most of the osteotomists who wrote accounts of their activities thought that antisepsis played a vital role in their success, and they vigorously promulgated this view in their publications.

The close links between antisepsis and osteotomy mean that the operation may be used as an indicator for antisepsis, with the number of osteotomies serving as a surrogate measure of surgical activity done under Listerian conditions. The discretionary nature of the operation contributes substantially to its value as such a measure; as it was done to relieve deformity rather than to save lives or treat trauma, the number of operations reflects the interests of surgeons much more closely than it does the exigencies of emergency practice. ${ }^{42}$ The abundance of publications on osteotomy, and its well defined nature, further add to its advantages as an indicator. The inescapable conclusion is that by the end of the 1870 s antiseptic practice had become routine in many major British hospitals. Surgeons were voting for it with their osteotomes. ${ }^{43}$

The other major event in the evolution of osteotomy was the development of the operative procedures themselves. Ogston's operation played a key role here. Although it was rapidly accepted as being technically straightforward and safe, its popularity also owed a good deal to the way in which Ogston disseminated information about it. His first paper was abundantly illustrated. He chose a German surgical meeting for his second round of publicity. Together with the subsequent publication of his paper in German, this accounted for the popularity of his operation in central Europe. Within less than two years

\footnotetext{
${ }^{40}$ Barwell, op. cit., note 18 above.

41 Macewen, op. cit., note 29 above.

42 Ogston put this nicely in his 1882 paper when describing the pre-operative disinfection of the skin required in "operations that involved serious danger, and that required to be successful at all hazards (operations of complaisance such as osteotomies and joint operations)" (Ogston, op. cit., note 11 above, p. 558).

43 "Osteotome" is here used in the sense proposed by Macwen (op. cit., note 29 above, pp. 68, 71) -a chisel-like instrument "bevelled on both sides, so as to resemble a very slender wedge. [To] distinguish it from the ordinary chisel, and at the same time be more euphemistic to a patient's ear, it has been termed an osteotome". The term has also been used to describe two other instruments, French bone forceps, and the remarkable early-nineteenthcentury chain saws of J. G. and B. Heine of Würzburg (see A. Rütt and W. Küsswetter, 'Würzburg die Wiege der Orthopaedie', in P. Baumgart, Vierhundert Jahre Universität Würzburg, Verlag Degener, Naustadt (Aisch), 1982).
} 


\section{T. H. Pennington}

after the publication of Ogston's first paper on osteotomy in March 1877, the operation, although not necessarily his, was being performed frequently in several centres (Graph 1). Other publications on the operation appeared even more quickly (Graph 2). While the ground may have been prepared for such a development through the wide promulgation of Lister's ideas, the acceptance of osteotomy was rapid. The public routes used by its proponents to publicize it, the scientific meeting and the weekly medical journal (particularly the Lancet, the British Medical Journal, and the Berliner Klinische Wochenschrift), probably played a vital role in facilitating such rapid acceptance. The short intervals between the development of the new osteotomy operations and their widespread adoption testify to the efficacy of such channels of communication, both of which had developed in the decades immediately preceding the introduction of antisepsis. They lend no support to the view that the interval between discovery and application is diminishing - in the medical field at least. 